\title{
ULTRASONIC AND MOLECULAR INTERACTION STUDIES OF CINNAMALDEHYDE WITH ACETONE IN n-HEXANE
}

\author{
C. Senthamil Selvi ${ }^{1, *}$, C. Thillaiyadi Valliammai ${ }^{2}$, P. Malliga ${ }^{1}$, C. Thenmozhi ${ }^{3}$ \\ and $V \cdot$ Kannappan ${ }^{4}$ \\ ${ }^{1}$ Department of Physics, Sathyabama University, Chennai, Tamilnadu, India \\ ${ }^{2}$ Department of Chemistry, A.V.V.M. Sri Pushpum College, Thanjavur, Tamilnadu, India \\ ${ }^{3}$ Department of Physics, PRIST University, Thanjavur, Tamilnadu, India \\ ${ }^{4}$ Department of Chemistry, Presidency College, Chennai, Tamilnadu, India \\ *E-mail: senthamilc@yahoo.co.in
}

\begin{abstract}
In this work, density, velocity and other acoustical parameters of cinnamaldehyde with acetone in n-hexane have been measured throughout the entire concentration range from the temperature of 293.15, 298.15, 303.15 and 308.15 $\mathrm{K}$ at atmospheric pressure. The excess velocity, excess adiabatic compressibility $\left(\mathrm{K}^{\mathrm{E}}\right)$, excess free length $\left(\mathrm{L}_{\mathrm{F}}^{\mathrm{E}}\right)$, excess molar volume $\left(\mathrm{V}_{\mathrm{m}}^{\mathrm{E}}\right)$ and excess impedance $\left(\mathrm{Z}^{\mathrm{E}}\right)$ have been computed. The sign and magnitude of these parameters indicate the strength of interactions and shows the formation of charge-transfer complex. Stability Constants $(\mathrm{K})$ and the thermodynamical parameters enthalpy $(\Delta \mathrm{H})$, Free Energy $(\Delta \mathrm{G})$, Entropy Changes $(\Delta \mathrm{S})$ and Correlation coefficient for formation of hydrogen bonded complexes are reported for such complexes. The formation constants of complexes of acetone with aromatic compounds depend on the structure of the donor and acceptor molecules.
\end{abstract}

Keywords: adiabatic compressibility, free volume and molecular interaction parameter, ultrasonic velocity

(C) RASĀYAN. All rights reserved

\section{INTRODUCTION}

Industry demands accessible oriented data on the thermodynamical properties (excess velocity, excess molar volumes and excess adiabatic compressibility) of a wide range of liquid mixtures. These properties not only offer reliable data and empirical rules for science and technology, but also enhance the nature and understanding the behavior of liquid mixtures. Acetone is miscible with water and serves as a main solvent and used for cleaning purposes in the laboratory. It is used in varnishes, paints and pharmaceutical drugs. The charge transfer complexation arises between some aromatic hydrocarbons and acetone as an acceptor has been studied ${ }^{1,2}$. This paper deals with the ultrasonic investigations on the complexation between acetone and electron donor molecules at various equimolar concentrations in nhexane medium at $293.15 \mathrm{~K}$ to $308.15 \mathrm{~K}$. The formation constants of the charge-transfer complexes were determined by the Benesi-Hildebrand equations (optical method) and compared with those obtained from Kannappan method (ultrasonic method).

\section{EXPERIMENTAL}

The liquid mixtures of various concentrations in mole fraction are prepared by taking AR grade chemicals, which are purified by standard methods. In the present work, the densities $(\rho)$ and Ultrasonic velocities (U) of ternary mixtures of crotonaldehyde with iodine in $n$-hexane at 293.15, 298.15, 303.15 and $308.15 \mathrm{~K}$ over the entire composition range are measured in different concentrations. The solvent has taken as accurately weighted amount of sample is dissolved in suitable solvent to obtain solution in the concentration range $1 \times 10^{-3} \mathrm{M}-1 \times 10^{-2} \mathrm{M}$. 


\section{Experimental procedure}

The ultrasonic velocity (U) has been measured by ultrasonic interferometer (Model F81 Mittal enterprises, New Delhi) at a frequency of $2 \mathrm{MHz}$ with an accuracy of $\pm 0.1 \%$. The viscosities ( $\eta$ ) of pure compounds and their mixtures are determined using Oswald's Viscometer calibrated with double distilled water. The densities $(\rho)$ of pure compounds and their solutions are measured accurately using $10 \mathrm{ml}$ specific gravity bottles in an electronic balance precisely and the accuracy in weighing is $\pm 0.1 \mathrm{mg}^{3}$. The temperatures are controlled by circulating water around the liquid cell from a thermostatically controlled water bath (accuracy $\pm 0.1^{\circ} \mathrm{C}$ ).

\section{Calculation of the derived parameters}

The various physical parameters are calculated from the measured values of density $(\rho)$, viscosity $(\eta)$ and ultrasonic velocity $(\mathrm{U})$. Using standard formula; the following acoustical parameters have been calculated:

$$
\text { Adiabatic compressibility }(\kappa)=1 / \mathrm{U}^{2} \rho
$$

Intermolecular free length $\left(\mathrm{L}_{\mathrm{f}}\right)$ has been calculated from the relation,

Where $\mathrm{K}$ is a temperature dependent constant.

$$
\mathrm{L}_{\mathrm{f}}=\mathrm{K} / \sqrt{ } \mathrm{U} \rho
$$

Free volume $\left(\mathrm{V}_{\mathrm{f}}\right)$ has been calculated from relation,

$$
\mathrm{V}_{\mathrm{f}}=\left(\mathrm{M}_{\mathrm{eff}} \mathrm{U} / \mathrm{K} \eta\right)^{3 / 2}
$$

The following equation (4) is used to compute internal pressure $\left(\pi_{\mathrm{i}}\right)$.

$$
\pi_{\mathrm{i}}=\operatorname{bRT}(\mathrm{K \eta} / \mathrm{U})^{1 / 2}\left(\rho^{2 / 3} / \mathrm{M}_{\mathrm{eff}}^{7 / 6}\right)
$$

Where, $\mathrm{M}_{\text {eff }}$ is the effective molecular weight, $\mathrm{T}$ is the absolute temperature; $\mathrm{K}$ is a constant, $\eta$ is the viscosity in $\mathrm{Nsm}^{-2}, \mathrm{U}$ the ultrasonic velocity in $\mathrm{ms}^{-1}, \rho$ is the density in $\mathrm{Kgm}^{-3}$

The acoustic impedance can be related as-

$$
\mathrm{Z}=\mathrm{U} \rho
$$

Other acoustical parameters such as relaxation time $(\tau)$, available volume $\left(v_{a}\right)$, cohesive energy $(\mathrm{CE})$, interaction parameter $\left(\chi_{\mathrm{i}}\right)$ and Lenord Jones Potential (LJP) are calculated using formula. Marwein and Bhat have proposed an equation to calculate the stability constants of donor - acceptor complexes in binary liquids which generally gives concentration dependent formation constant values. Recently, Kannappan et al have proposed an equation to calculate the formation constant values of the charge transfer complexes, appreciable to weak complexes and in very dilute solutions. The stability constant is calculated using the relation-

$$
\mathrm{K}=\mathrm{Y} /(\mathrm{b}-\mathrm{y})^{2} \mathrm{dm}^{3} \mathrm{~mol}^{-1}
$$

Where, $\mathrm{Y}=\left(\mathrm{a}-\mathrm{k}^{1 / 2} \mathrm{~b}\right) /\left(\mathrm{k}-\mathrm{k}^{1 / 2}\right) ; \mathrm{k}=\mathrm{x} / \mathrm{y}$.

The free energy of formation is calculated using the relation-

$$
\Delta \mathrm{G}=-\mathrm{RT} \ln \mathrm{K}
$$

Where, $\mathrm{R}$ is the gas constant, $\mathrm{T}$ is the temperature in Kelvin and $\mathrm{K}$ is the formation constant.

The value of enthalpy change $\Delta H$ is obtained from the plot of $\log \mathrm{K}$ against $1 / \mathrm{T}$.

The entropy of formation of the complex is calculated using-

$$
\Delta \mathrm{S}=(\Delta \mathrm{H}-\Delta \mathrm{G}) / \mathrm{T}
$$


RASĀYAN J. Chem.

Vol. 10 | No. 1 |271 -278 | January - March | 2017

The excess thermodynamic parameter is defined as the difference between the experimental and ideal mixture values. It is a measure of the non-ideality of the system as a consequence of associative or of other interactions.

Table-1: Ultrasonic velocity (U), Density ( $\rho$ ), Viscosity ( $\eta)$, Adiabatic compressibility ( $\kappa)$, Intermolecular free length $\left(\mathrm{L}_{\mathrm{f}}\right)$, Specific acoustic impedance $(\mathrm{Z})$, Absorption coefficient $\left(\alpha / \mathrm{f}^{2}\right)$, Molecular interaction parameter $\left(\chi_{\mathrm{u}}\right)$ and Relaxation time $(\tau)$ of acetone with cinnamaldehyde in n-hexane solution at 293.15 and $298.15 \mathrm{~K}$

\begin{tabular}{|c|c|c|c|c|c|c|c|c|c|}
\hline $\begin{array}{c}\text { "Conc., } \\
\text { M }\end{array}$ & $\begin{array}{c}\mathrm{U} \\
\mathrm{ms}^{-1}\end{array}$ & $\begin{array}{c}\rho \\
\mathrm{Kgm}^{-3}\end{array}$ & $\begin{array}{l}\eta / 10^{-4} \\
\mathrm{Nsm}^{-2}\end{array}$ & $\begin{array}{l}\mathrm{K} / 10^{-10} \\
\mathrm{~kg}^{-1} \mathrm{~ms}^{2}\end{array}$ & $\begin{array}{c}\mathrm{L}_{\mathrm{f}} / \\
10^{-11} \mathrm{~m}\end{array}$ & $\begin{array}{c}\mathrm{Z} / 10^{4} \\
\mathrm{Kgm}^{-2} \mathrm{~s}^{-1}\end{array}$ & $\begin{array}{l}\alpha / \mathrm{f}^{2} / 10^{-14} \\
\mathrm{Npm}^{-1} \mathrm{~s}^{2}\end{array}$ & $\chi_{u}$ & $\begin{array}{c}\tau / 10^{-13} \\
\operatorname{secs}\end{array}$ \\
\hline \multicolumn{10}{|c|}{$293.15 \mathrm{~K}$} \\
\hline 0.001 & 1089.5 & 669.0 & 5.1 & 12.59 & 7.1 & 72.9 & 10.8 & 0.0259 & 8.5 \\
\hline 0.002 & 1089.2 & 669.1 & 5.0 & 12.60 & 7.1 & 72.9 & 10.8 & 0.0252 & 8.5 \\
\hline 0.003 & 1088.1 & 669.2 & 5.0 & 12.62 & 7.1 & 72.8 & 10.8 & 0.0230 & 8.5 \\
\hline 0.004 & 1091.3 & 669.3 & 5.0 & 12.55 & 7.1 & 73.0 & 10.7 & 0.0294 & 8.4 \\
\hline 0.005 & 1090.1 & 669.4 & 5.0 & 12.57 & 7.1 & 73.0 & 10.6 & 0.0265 & 8.4 \\
\hline 0.006 & 1089.4 & 669.5 & 4.9 & 12.59 & 7.1 & 72.9 & 10.4 & 0.0250 & 8.2 \\
\hline 0.007 & 1086.5 & 669.6 & 4.3 & 12.65 & 7.1 & 72.8 & 9.10 & 0.0194 & 7.2 \\
\hline 0.008 & 1085.2 & 669.7 & 4.0 & 12.68 & 7.1 & 72.7 & 8.67 & 0.0169 & 6.8 \\
\hline 0.009 & 1083.1 & 669.8 & 4.0 & 12.73 & 7.1 & 72.6 & 8.71 & 0.0128 & 6.8 \\
\hline 0.010 & 1082.4 & 669.9 & 4.0 & 12.74 & 7.1 & 72.5 & 8.68 & 0.0113 & 6.8 \\
\hline \multicolumn{10}{|c|}{$298.15 \mathrm{~K}$} \\
\hline 0.001 & 1087.1 & 668.3 & 5.0 & 12.66 & 7.1 & 72.7 & 10.8 & 0.0214 & 8.5 \\
\hline 0.002 & 1086.3 & 668.4 & 5.0 & 12.68 & 7.1 & 72.6 & 10.8 & 0.0197 & 8.5 \\
\hline 0.003 & 1086.2 & 668.5 & 5.0 & 12.68 & 7.1 & 72.6 & 10.8 & 0.0194 & 8.5 \\
\hline 0.004 & 1088.3 & 668.6 & 5.0 & 12.63 & 7.1 & 72.8 & 10.8 & 0.0237 & 8.5 \\
\hline 0.005 & 1087.1 & 668.7 & 5.0 & 12.65 & 7.1 & 72.7 & 10.8 & 0.0208 & 8.5 \\
\hline 0.006 & 1090.4 & 668.8 & 5.0 & 12.58 & 7.1 & 72.9 & 10.7 & 0.0269 & 8.5 \\
\hline 0.007 & 1090.9 & 668.9 & 5.1 & 12.56 & 7.1 & 73.0 & 10.7 & 0.0277 & 8.5 \\
\hline 0.008 & 1091.1 & 669.0 & 5.0 & 12.56 & 7.1 & 73.0 & 10.7 & 0.0279 & 8.4 \\
\hline 0.009 & 1093.2 & 669.1 & 5.0 & 12.51 & 7.1 & 73.2 & 10.6 & 0.0318 & 8.4 \\
\hline 0.010 & 1094.2 & 669.2 & 5.1 & 12.48 & 7.1 & 73.2 & 10.6 & 0.0335 & 8.4 \\
\hline
\end{tabular}

Table-2: Ultrasonic velocity (U), Density ( $\rho$ ), Viscosity ( $)$, Adiabatic compressibility ( $\kappa)$, Intermolecular free length $\left(\mathrm{L}_{\mathrm{f}}\right)$, Specific acoustic impedance $(\mathrm{Z})$, Absorption coefficient $\left(\alpha / \mathrm{f}^{2}\right)$, Molecular interaction parameter $\left(\chi_{\mathrm{u}}\right)$ and Relaxation time $(\tau)$ of acetone with cinnamaldehyde in n-hexane solution at 303.15 and $308.15 \mathrm{~K}$

\begin{tabular}{|c|c|c|c|c|c|c|c|c|c|}
\hline $\begin{array}{c}\text { *Conc., } \\
\text { M }\end{array}$ & $\begin{array}{c}\mathrm{U} \\
\mathrm{ms}^{-1}\end{array}$ & $\begin{array}{c}\rho \\
\mathrm{Kgm}^{-3}\end{array}$ & $\begin{array}{l}\eta / 10^{-4} \\
\mathrm{Nsm}^{-2}\end{array}$ & $\begin{array}{c}\kappa / 10^{-10} \\
\mathrm{~kg}^{-1} \mathrm{~ms}^{2}\end{array}$ & $\begin{array}{c}\mathrm{L}_{\mathrm{f}} / \\
10^{-11} \mathrm{~m}\end{array}$ & $\begin{array}{c}\mathrm{Z} / 10^{4} \\
\mathrm{Kgm}^{-2} \mathrm{~s}^{-1}\end{array}$ & $\begin{array}{l}\alpha / \mathrm{f}^{2} / 10^{-14} \\
\mathrm{Npm}^{-1} \mathrm{~s}^{2}\end{array}$ & $\chi_{\mathrm{u}}$ & $\begin{array}{c}\tau / 10^{-13} \\
\text { secs }\end{array}$ \\
\hline \multicolumn{10}{|c|}{$303.15 \mathrm{~K}$} \\
\hline 0.001 & 1064.5 & 666.41 & 5.2 & 13.24 & 7.3 & 70.9 & 11.8 & -0.0208 & 9.1 \\
\hline 0.002 & 1063.4 & 666.52 & 5.0 & 13.27 & 7.3 & 70.9 & 11.6 & -0.0228 & 8.9 \\
\hline 0.003 & 1061.4 & 666.62 & 5.0 & 13.32 & 7.3 & 70.8 & 11.6 & -0.0266 & 8.9 \\
\hline 0.004 & 1064.0 & 666.74 & 5.0 & 13.25 & 7.3 & 70.9 & 11.5 & -0.0215 & 8.9 \\
\hline 0.005 & 1063.9 & 666.82 & 5.0 & 13.25 & 7.3 & 70.9 & 11.5 & -0.0224 & 8.9 \\
\hline 0.006 & 1063.2 & 666.93 & 5.0 & 13.26 & 7.3 & 70.9 & 11.5 & -0.0237 & 8.9 \\
\hline 0.007 & 1062.9 & 667.03 & 5.0 & 13.27 & 7.3 & 70.9 & 11.5 & -0.0244 & 8.8 \\
\hline 0.008 & 1059.6 & 667.14 & 4.9 & 13.35 & 7.3 & 70.7 & 11.3 & -0.0306 & 8.7 \\
\hline 0.009 & 1058.1 & 667.21 & 4.8 & 13.39 & 7.3 & 70.6 & 11.1 & -0.0334 & 8.5 \\
\hline 0.010 & 1057.9 & 667.33 & 4.7 & 13.39 & 7.3 & 70.6 & 11.0 & -0.0339 & 8.4 \\
\hline \multicolumn{10}{|c|}{$308.15 \mathrm{~K}$} \\
\hline 0.001 & 1047.9 & 665.1 & 5.1 & 13.69 & 7.4 & 69.7 & 12.2 & -0.0510 & 9.3 \\
\hline 0.002 & 1047.4 & 665.2 & 5.0 & 13.70 & 7.4 & 69.7 & 12.1 & -0.0520 & 9.2 \\
\hline 0.003 & 1046.0 & 665.3 & 5.0 & 13.74 & 7.4 & 69.6 & 12.0 & -0.0547 & 9.1 \\
\hline
\end{tabular}


RASĀYAN J. Chem.

Vol. 10 | No. 1 |271 -278 | January - March | 2017

\begin{tabular}{l|l|l|l|l|l|l|l|l|l}
\hline 0.004 & 1048.6 & 665.4 & 5.0 & 13.67 & 7.4 & 69.8 & 12.0 & -0.0496 & 9.1 \\
\hline 0.005 & 1047.0 & 665.5 & 4.9 & 13.71 & 7.4 & 69.7 & 11.9 & -0.0531 & 9.0 \\
\hline 0.006 & 1046.2 & 665.6 & 4.9 & 13.73 & 7.4 & 69.6 & 12.0 & -0.0547 & 9.0 \\
\hline 0.007 & 1045.1 & 665.7 & 4.9 & 13.75 & 7.4 & 69.6 & 12.0 & -0.0568 & 9.0 \\
\hline 0.008 & 1044.6 & 665.8 & 4.9 & 13.76 & 7.4 & 69.6 & 12.0 & -0.0578 & 9.0 \\
\hline 0.009 & 1043.7 & 665.9 & 4.9 & 13.79 & 7.4 & 69.5 & 12.0 & -0.0596 & 9.0 \\
\hline 0.010 & 1043.1 & 666.0 & 4.9 & 13.80 & 7.4 & 69.5 & 12.0 & -0.0608 & 9.1 \\
\hline
\end{tabular}

Table-3: Molar volume $\left(\mathrm{V}_{\mathrm{m}}\right)$, Available volume $\left(\mathrm{V}_{\mathrm{a}}\right)$, Free volume $\left(\mathrm{V}_{\mathrm{f}}\right)$, Internal pressure $\left(\pi_{\mathrm{i}}\right)$, Molar cohesive energy (MCE), Lenard Jones Potential (LJP), Molar sound velocity (R), Molar compressibility (W) and Surface tension $(\sigma)$ of acetone with cinnamaldehyde in n-hexane solution at 293.15 and $298.15 \mathrm{~K}$

\begin{tabular}{|c|c|c|c|c|c|c|c|c|}
\hline $\begin{array}{c}{ }^{*} \text { Conc., } \\
\text { M }\end{array}$ & $\begin{array}{c}\mathrm{V}_{\mathrm{m}} / 10^{-5} \\
\mathrm{~m}^{3} \mathrm{~mole}^{-1}\end{array}$ & $\begin{array}{c}\mathrm{V}_{\mathrm{a}} / 10^{-5} \\
\mathrm{~m}^{3} \mathrm{~mole}^{-1}\end{array}$ & $\begin{array}{c}\pi_{\mathrm{i}} / 10^{8} \\
\mathrm{~atm}\end{array}$ & $\begin{array}{c}\mathrm{MCE} / 10^{4} \\
\mathrm{~kJ} \mathrm{~mol}^{-1}\end{array}$ & LJP & $\begin{array}{l}\mathrm{R} / \\
10^{-3}\end{array}$ & $\begin{array}{l}\mathrm{W} / \\
10^{-3}\end{array}$ & $\begin{array}{c}\sigma \\
\mathrm{Nm}^{-1}\end{array}$ \\
\hline \multicolumn{9}{|c|}{$293.15 \mathrm{~K}$} \\
\hline 0.001 & 12.88 & 4.11 & 2.900 & 3.7 & 5.8 & 1.3 & 2.4 & 15157 \\
\hline 0.002 & 12.88 & 4.11 & 2.896 & 3.7 & 5.8 & 1.3 & 2.4 & 15153 \\
\hline 0.003 & 12.88 & 4.12 & 2.895 & 3.7 & 5.8 & 1.3 & 2.4 & 15132 \\
\hline 0.004 & 12.88 & 4.09 & 2.890 & 3.7 & 5.9 & 1.3 & 2.4 & 15201 \\
\hline 0.005 & 12.88 & 4.10 & 2.880 & 3.7 & 5.8 & 1.3 & 2.4 & 15178 \\
\hline 0.006 & 12.87 & 4.11 & 2.848 & 3.7 & 5.8 & 1.3 & 2.4 & 15166 \\
\hline 0.007 & 12.87 & 4.13 & 2.665 & 3.4 & 5.7 & 1.3 & 2.4 & 15108 \\
\hline 0.008 & 12.87 & 4.14 & 2.594 & 3.3 & 5.6 & 1.3 & 2.4 & 15083 \\
\hline 0.009 & 12.87 & 4.16 & 2.595 & 3.3 & 5.6 & 1.3 & 2.4 & 15041 \\
\hline 0.010 & 12.87 & 4.16 & 2.589 & 3.3 & 5.5 & 1.3 & 2.4 & 15029 \\
\hline \multicolumn{9}{|c|}{$298.15 \mathrm{~K}$} \\
\hline 0.001 & 12.90 & 4.13 & 2.943 & 3.8 & 5.7 & 1.3 & 2.4 & 15091 \\
\hline 0.002 & 12.89 & 4.14 & 2.936 & 3.8 & 5.7 & 1.3 & 2.4 & 15077 \\
\hline 0.003 & 12.89 & 4.14 & 2.939 & 3.8 & 5.7 & 1.3 & 2.4 & 15076 \\
\hline 0.004 & 12.89 & 4.12 & 2.943 & 3.8 & 5.8 & 1.3 & 2.4 & 15123 \\
\hline 0.005 & 12.89 & 4.13 & 2.948 & 3.8 & 5.7 & 1.3 & 2.4 & 15100 \\
\hline 0.006 & 12.89 & 4.11 & 2.944 & 3.8 & 5.8 & 1.3 & 2.4 & 15171 \\
\hline 0.007 & 12.89 & 4.10 & 2.948 & 3.8 & 5.9 & 1.3 & 2.4 & 15184 \\
\hline 0.008 & 12.89 & 4.10 & 2.938 & 3.8 & 5.9 & 1.3 & 2.4 & 15190 \\
\hline 0.009 & 12.88 & 4.08 & 2.941 & 3.8 & 5.9 & 1.3 & 2.4 & 15236 \\
\hline 0.010 & 12.88 & 4.07 & 2.942 & 3.8 & 6.0 & 1.3 & 2.4 & 15260 \\
\hline
\end{tabular}

Table-4: Molar volume $\left(\mathrm{V}_{\mathrm{m}}\right)$, Available volume $\left(\mathrm{V}_{\mathrm{a}}\right)$, Free volume $\left(\mathrm{V}_{\mathrm{f}}\right)$, Internal pressure $\left(\pi_{\mathrm{i}}\right)$, Molar cohesive energy (MCE), Lenard Jones Potential (LJP), Molar sound velocity (R), Molar compressibility (W) and Surface tension $(\sigma)$ of acetone with cinnamaldehyde in $n$-hexane solution at 303.15 and $308.15 \mathrm{~K}$

\begin{tabular}{|c|c|c|c|c|c|c|c|c|}
\hline $\begin{array}{c}\text { "Conc., } \\
\text { M }\end{array}$ & $\begin{array}{c}\mathrm{V}_{\mathrm{m}} / 10^{-5} \\
\mathrm{~m}^{3} \mathrm{~mole}^{-1} \\
\end{array}$ & $\begin{array}{c}\mathrm{V}_{\mathrm{a}} / 10^{-5} \\
\mathrm{~m}^{3} \mathrm{~mole}^{-1}\end{array}$ & $\begin{array}{c}\pi_{\mathrm{i}} / 10^{8} \\
\mathrm{~atm} \\
\end{array}$ & $\begin{array}{c}\mathrm{MCE} / 10^{4} \\
\mathrm{~kJ} \mathrm{~mol}{ }^{-1}\end{array}$ & LJP & $\begin{array}{l}\mathrm{R} / \\
10^{-3} \\
\end{array}$ & $\begin{array}{l}\mathrm{W} / \\
10^{-3} \\
\end{array}$ & $\begin{array}{c}\sigma \\
\mathrm{Nm}^{-1} \\
\end{array}$ \\
\hline \multicolumn{9}{|c|}{$303.15 \mathrm{~K}$} \\
\hline 0.001 & 12.93 & 4.33 & 3.056 & 4.0 & 4.9 & 1.3 & 2.4 & 14580 \\
\hline 0.002 & 12.93 & 4.34 & 3.020 & 3.9 & 4.9 & 1.3 & 2.4 & 14561 \\
\hline 0.003 & 12.93 & 4.35 & 3.018 & 3.9 & 4.8 & 1.3 & 2.4 & 14522 \\
\hline 0.004 & 12.93 & 4.33 & 3.017 & 3.9 & 4.9 & 1.3 & 2.4 & 14578 \\
\hline 0.005 & 12.93 & 4.33 & 3.017 & 3.9 & 4.9 & 1.3 & 2.4 & 14577 \\
\hline 0.006 & 12.92 & 4.34 & 3.018 & 3.9 & 4.9 & 1.3 & 2.4 & 14566 \\
\hline 0.007 & 12.92 & 4.34 & 3.011 & 3.9 & 4.9 & 1.3 & 2.4 & 14562 \\
\hline 0.008 & 12.92 & 4.36 & 2.980 & 3.9 & 4.8 & 1.3 & 2.4 & 14497 \\
\hline 0.009 & 12.92 & 4.38 & 2.943 & 3.8 & 4.7 & 1.3 & 2.4 & 14468 \\
\hline 0.010 & 12.90 & 4.38 & 2.928 & 3.8 & 4.7 & 1.3 & 2.4 & 14466 \\
\hline
\end{tabular}


RASĀYAN J. Chem.

Vol. 10 | No. 1 | 271 -278 | January - March | 2017

\begin{tabular}{l|l|l|l|l|l|l|l|l}
\hline \multicolumn{9}{|c|}{$308.15 \mathrm{~K}$} \\
\hline 0.001 & 12.96 & 4.47 & 3.100 & 4.0 & 4.4 & 1.3 & 2.4 & 14214 \\
\hline 0.002 & 12.96 & 4.48 & 3.086 & 4.0 & 4.4 & 1.3 & 2.4 & 14206 \\
\hline 0.003 & 12.96 & 4.49 & 3.071 & 4.0 & 4.3 & 1.3 & 2.4 & 14179 \\
\hline 0.004 & 12.95 & 4.46 & 3.077 & 4.0 & 4.4 & 1.3 & 2.4 & 14234 \\
\hline 0.005 & 12.95 & 4.48 & 3.063 & 4.0 & 4.4 & 1.3 & 2.4 & 14204 \\
\hline 0.006 & 12.95 & 4.48 & 3.065 & 4.0 & 4.3 & 1.3 & 2.4 & 14190 \\
\hline 0.007 & 12.95 & 4.49 & 3.063 & 4.0 & 4.3 & 1.3 & 2.4 & 14170 \\
\hline 0.008 & 12.95 & 4.49 & 3.062 & 4.0 & 4.3 & 1.3 & 2.4 & 14162 \\
\hline 0.009 & 12.95 & 4.50 & 3.060 & 4.0 & 4.3 & 1.3 & 2.4 & 14145 \\
\hline 0.010 & 12.94 & 4.51 & 3.065 & 4.0 & 4.2 & 1.3 & 2.4 & 14135 \\
\hline
\end{tabular}

\section{RESULTS AND DISCUSSION}

The ultrasonic velocity $(U)$, density $(\rho)$, viscosity $(\eta)$, adiabatic compressibility $(\kappa)$, free length $\left(L_{f}\right)$, free volume $\left(\mathrm{V}_{\mathrm{f}}\right)$, internal pressure $\left(\pi_{\mathrm{i}}\right)$ and molar volume $(\mathrm{Vm})$ of cinnamaldehyde with acetone in hexane have been measured at 293.15, 298.15,303.15 and 308.15 K and are presented in Table-1 and 2. The values of impedance, relaxation time, interaction parameter, cohesive energy and free energy of activation have been calculated and presented in Table- 3 and 4 . The plots of ultrasonic velocity versus concentration are shown in Figure-1. It is found that the ultrasonic velocity shows maximum $0.004 \mathrm{M}$ and then gradually decreases. It shows gradual increase trend at $298.15 \mathrm{~K}$. As the temperature increases, the velocity value decreases in all the temperatures were studied. The variation of ultrasonic velocity through the mixtures depends on the values of $\mathrm{L}_{\mathrm{f}}$. The observed increase in velocity and the corresponding decrease in free length with composition for all the systems are in accordance with the view proposed by Eyring and Kincaid. This is due to the result of weakening of molecules interaction forces between donor and acceptor ${ }^{4}$. It shows the non - linear behavior of velocity with concentration indicates the formation of charge transfer complex between the molecules. Density slightly increases with increase in concentration and viscosity decreases with increase in concentration.

The values of adiabatic compressibility $(\kappa)$ and intermolecular free length $\left(\mathrm{L}_{\mathrm{f}}\right)$ shows an inverse behavior as compound to the variation in ultrasonic velocity as shown in Figure-2. This increase in intermolecular free length increases leads to an increase in adiabatic compressibility with increase in temperature. These results are supported by the decrease in velocity in the donor - acceptor complex. This change in density and viscosity may be due to thermal effect of the molecular of the components with increase in temperature. The molecular interaction studies in solution provide information regarding the internal structure, molecular association, complex formation and internal pressure ${ }^{5}$. The values of free length remain almost constant. This is added to support of the charge complex construction between the acetone and cinnamaldehyde. These results are supported by the decrease in velocity in the donor - acceptor complex ${ }^{6}$. This change in density and viscosity may be due to thermal effect of the molecular of the components with increase in temperature.

The molecular interaction studies in solution provide information regarding the internal structure, molecular association, complex formation and internal pressure. The values of free length remain almost constant. This is added to support of the charge complex construction between the compounds. The value of $\mathrm{Z}$ shows the decreasing trend in all the temperatures except $298.15 \mathrm{~K}$. The value of molar volume $(\mathrm{Vm})$ decreases with increase in concentration and increases with increase in temperature. Absorption coefficient $\left(\alpha / \mathrm{f}^{2}\right)$ and relaxation time $(\tau)$ are given in Tables 1-2. These values of $\alpha / \mathrm{f}^{2}$ and $\tau$ are computed from the ultrasonic velocity, viscosity and density. It is observed that the values of $\alpha / \mathrm{f}^{2}$ and $\tau$ are almost constant for a given system but varying from one system to another system. It shows the intrinsic properties of the charge transfer complexation. When the temperature is increased, the values of $\alpha / \mathrm{f}^{2}$ and $\tau$ increases for all the systems.

The molecular interaction parameter $\chi_{\mathrm{u}}$ shows positive at 293.15 and $298.15 \mathrm{~K}$ and shows negative values at 303.15 and $308.15 \mathrm{~K}$ as shown in Figure 3. Positive values of molecular interaction parameter shows that the less stable complex may be formed. The negative value of molecular interaction parameter shows 
the extent of complexation. The molar cohesive energy increases with the increase temperature. It is observed that the available volume increases with increase in concentration and it is increases with increase in temperatures. The value of molar volume decreases with increase in concentration and increases with increase in temperature. For acetone - cinnamaldehyde, the value of LJP decreases with increase in concentration except $298 \mathrm{~K}$. It is observed that the LJP values decreases at low concentration and again it increases at higher concentration.

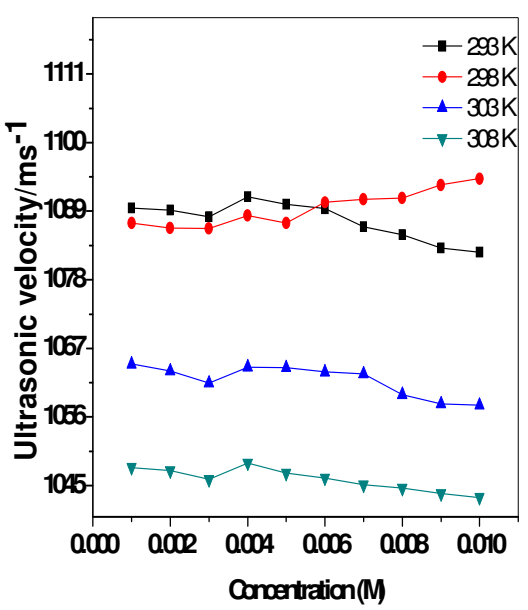

Fig.-1: Plots of U Vs concentration

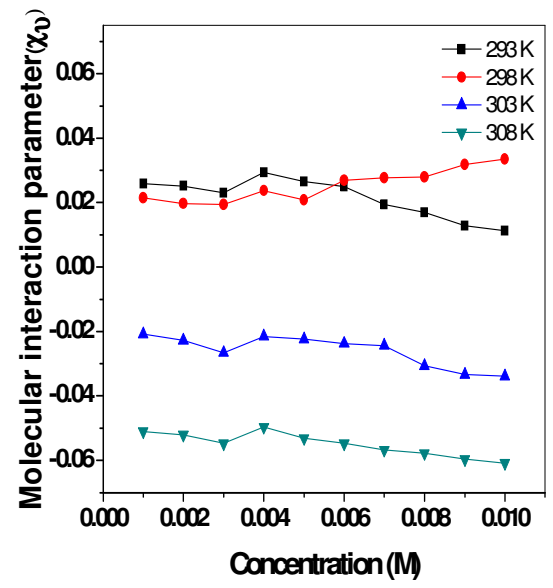

Fig.-3: Plots of molecular interaction parameter $\left(\chi_{\mathrm{u}}\right)$ Vs concentration

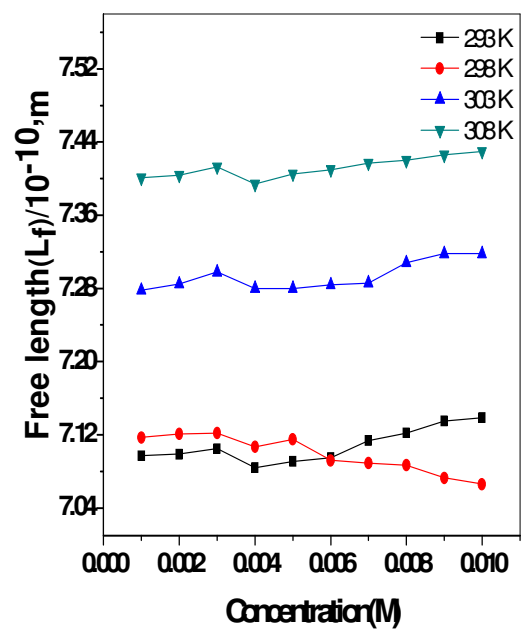

Fig.-2: Plots of $\mathrm{L}_{\mathrm{f}}$ Vs concentration

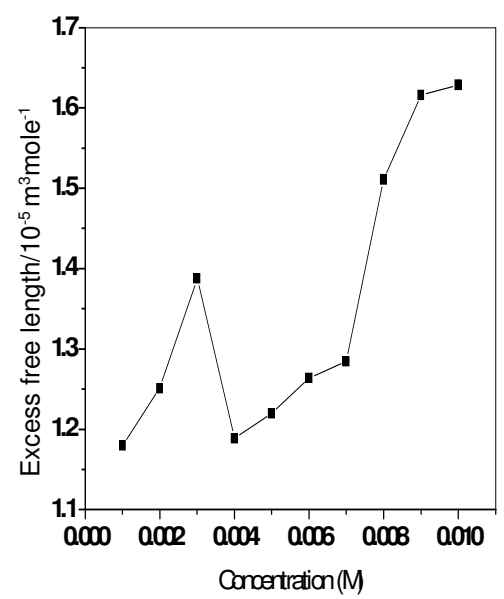

Fig.-4: Plot of excess free length Vs concentration at $303 \mathrm{~K}$

The variations of LJP values are similar of ultrasonic velocity. It is investigated that the values of molar sound velocity and molar compressibility have small deviation with concentration. It shows that the charge transfer complexes arise between the acetone and the carbonyl compound. It is observed that the values of surface tension decreases with increase in temperature. Table- 3 and 4 shows that the value of $\sigma$ decreases with increase in concentration. It is observed that the values of excess velocity $\left(\mathrm{U}^{\mathrm{E}}\right)$ and excess molar volume $\left(\mathrm{V}_{\mathrm{m}}{ }^{\mathrm{E}}\right)$ shows negative over the entire composition range for all the concentrations as shown 
in Table-5. It is observed that the values of $\kappa^{\mathrm{E}}$ shows positive excess values in all concentration. The excess compressibility is approximately proportional to the strength of the interaction between unlike molecules in the mixture ${ }^{7}$. Excess adiabatic compressibility are positive over the entire composition range is attributed to weak dipolar interaction between unlike molecules. It shows that the negative excess values indicate the formation of strong charge transfer complex.

Table-5: Excess velocity $\left(\mathrm{U}^{\mathrm{E}}\right)$, Excess adiabatic compressibility $\left(\kappa^{\mathrm{E}}\right)$, Excess free length $\left(\mathrm{L}_{\mathrm{F}}^{\mathrm{E}}\right)$, Excess molar volume $\left(\mathrm{V}_{\mathrm{m}}^{\mathrm{E}}\right)$ and Excess impedance $\left(\mathrm{Z}^{\mathrm{E}}\right)$ of acetone with cinnamaldehyde in $\mathrm{n}$-hexane at $303.15 \mathrm{~K}$

\begin{tabular}{c|c|c|c|c|c}
\hline $\begin{array}{c}\text { Conc., } \\
\mathrm{M}\end{array}$ & $\begin{array}{c}\mathrm{U}^{\mathrm{E}} \\
\mathrm{ms}^{-1}\end{array}$ & $\begin{array}{c}\mathrm{K}^{\mathrm{E}} / 10^{-11} \\
\mathrm{Kg}^{-1} \mathrm{~ms}^{2}\end{array}$ & $\begin{array}{c}\mathrm{L}_{\mathrm{F}}^{\mathrm{E}} / 10^{-12} \\
\mathrm{~m}\end{array}$ & $\begin{array}{c}\mathrm{V}_{\mathrm{m}}^{\mathrm{E}} / 10^{-5} \\
\mathrm{~m}^{3} \mathrm{~mole}^{-1}\end{array}$ & $\begin{array}{c}\mathrm{Z}^{\mathrm{E}} / 10^{5} \\
\mathrm{Kgm}^{-2} \mathrm{~s}^{-1}\end{array}$ \\
\hline 0.001 & -11.22 & 4.255 & 1.180 & -2.483 & 7.094 \\
\hline 0.002 & -12.34 & 4.511 & 1.251 & -2.483 & 7.088 \\
\hline 0.003 & -14.41 & 5.007 & 1.388 & -2.484 & 7.076 \\
\hline 0.004 & -11.63 & 4.292 & 1.189 & -2.490 & 7.094 \\
\hline 0.005 & -12.11 & 4.386 & 1.220 & -2.485 & 7.094 \\
\hline 0.006 & -12.83 & 4.542 & 1.264 & -2.486 & 7.091 \\
\hline 0.007 & -13.20 & 4.613 & 1.285 & -2.487 & 7.090 \\
\hline 0.008 & -16.57 & 5.434 & 1.511 & -2.487 & 7.069 \\
\hline 0.009 & -18.14 & 5.814 & 1.616 & -2.487 & 7.060 \\
\hline 0.010 & -18.41 & 5.857 & 1.629 & -2.488 & 7.060 \\
\hline
\end{tabular}

Normally, the dispersion forces make a positive contribution to the excess values while dipole - dipole, dipole - induced dipole charge transfer interaction and hydrogen bonding between unlike components make negative contributions. The positive excess values of $\kappa^{\mathrm{E}}$ and $\mathrm{L}_{\mathrm{F}}^{\mathrm{E}}$ shows weak charge transfer complex formation between acetone and acceptor in n-hexane medium at $303.15 \mathrm{~K}$. The value of $\mathrm{L}_{\mathrm{F}}^{\mathrm{E}}$ shows the maximum value at $0.003 \mathrm{M}$ and shows slight decreasing trend. It shows increasing trend with increase in concentration as shown in Figure-4. It is established to the magnitude and sign of excess volumes.

(i) Difference in shape and size of the components (ii) loss of dipolar association (iii) complex formation and (iv) dipole - dipole, dipole - induced dipole interactions. The negative excess molar volume has a negative values shows specific, relatively strong interactions close packed structure and less compressibility structure of certain concentration. The excess impedance $\left(Z^{\mathrm{E}}\right)$ values are positive over the entire composition range for all the system investigated. It is observed that the $Z^{\mathrm{E}}$ values decreases with increase in concentration.

The formation constant $(\mathrm{K})$ are computed for these complexes using by the method of Kannappan. The thermodynamic stability of donor - acceptor complexes formed between the acetone and cinnamaldehyde can be compared by determining the stability constants of these complexes at different temperatures as shown in Table-6.

Table-6: Stability Constants (K), Enthalpy $(\Delta \mathrm{H})$, Free Energy $(\Delta \mathrm{G})$, Entropy Changes $(\Delta \mathrm{S})$ and Correlation coefficient for formation of hydrogen bonded complexes of cinnamaldehyde with acetone in $\mathrm{n}$-hexane

\begin{tabular}{c|c|c|c|c|c|c}
\hline Systems & $\begin{array}{c}\mathrm{T} / \\
\mathrm{K}\end{array}$ & $\begin{array}{c}\mathrm{K} / \\
\mathrm{M}^{-1}\end{array}$ & $\begin{array}{c}\Delta \mathrm{H} / \\
\mathrm{kJ} \mathrm{mole}^{-1}\end{array}$ & $\begin{array}{c}\Delta \mathrm{G}_{298 \mathrm{~K}} / \\
\mathrm{kJ} \mathrm{mole}^{-1}\end{array}$ & $\begin{array}{c}\Delta \mathrm{S}_{298 \mathrm{~K}} / \\
\mathrm{J} \mathrm{K}^{-1} \mathrm{~mole}^{-1}\end{array}$ & $\begin{array}{c}\text { Correlation } \\
\text { coefficient }\end{array}$ \\
\hline Cinnamaldehyde & 293 & 60.0 & & & & \\
\hline & 298 & 46.8 & -19.516 & -9.526 & -33.516 & 0.99944 \\
\hline & 303 & 34.9 & & & & \\
\hline & 308 & 23.1 & & & & \\
\hline
\end{tabular}

The values of $\mathrm{K}$ can be used to assess the stabilities of the charge transfer complex formed between acetone and the donor molecules. The stability constant value decreases with increase in temperature and is almost independent of concentration at $303.15 \mathrm{~K}$. 
The formation constant of the complex depends upon the structure of acetone as well as the structure of aldehyde. For a given aldehyde, the stability constant increases when electron donating group is present near the carbonyl group. The thermodynamic parameters such as free energy change $(\Delta \mathrm{G})$, enthalpy changes $(\Delta \mathrm{H})$ and entropy changes $(\Delta \mathrm{S})$ for the formation of donor-acceptor complexes are determined. The enthalpy change values are obtained from the plots of $\operatorname{lnK} \mathrm{Vs} 1 / \mathrm{T}$. The plot are linear with positive slope indicating that the enthalpy change values are negative for the formation of the donor - acceptor complexes. Therefore, it can be inferred that the formation of the complexes between acetone and cinnamaldehyde in $n$-hexane solution is exothermic. The correlation coefficient shows good agreement between $\ln \mathrm{K}$ Vs $1 / \mathrm{T}$ as shown in Figure-5. The trend in free energy of formation correlates with the trend in the stability constants. The entropy change for the formation of donor - acceptor complexes between acetone and aldehydes are negative.

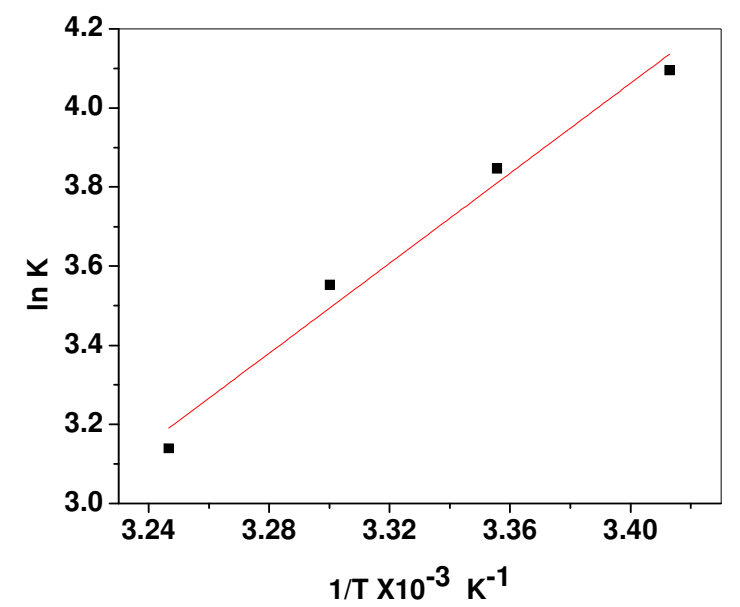

Fig.-5: Plot of 1/T Vs ln K of acetone with cinnamaldehyde in n-hexane solution

\section{CONCLUSION}

Molecular interaction parameter $\left(\chi_{\mathrm{u}}\right)$ shows an indicative of the extent of deviation from ideal behavior which may be due to complexation. These values are positive indicating the formation of complex between aldehydes and acetone in n-hexane medium at 293.15 and $298.15 \mathrm{~K}$ shows positive values are observed. It indicates the extension of complexation. Positive values of molecular interaction parameter shows that the less stable complex may be formed. The negative value of molecular interaction parameter shows the extent of complexation at 303.15 and $308.15 \mathrm{~K}$. This is also supported by the excess free length values.

\section{REFERENCES}

1. J. D. Pandey, R. Dey and R. Verma, Physics and Chemistry of Liquids, 14(2), 145 (2003).

2. B. S. Santhi, D. Krishnamurthy, V. Kannappan and R. Kumar, Journal of Molecular Liquids, 120(2), 188 (2013).

3. V. Ulagendran, R. Kumar,S. Jayakumar and V. Kannappan, Journal of Molecular Liquids, 67(2), 148 (2009).

4. C. Senthamil Selvi, K. Venkataramanan, V. Kannappan, C.Thenmozhi4 and S. Ravichandran, Asian Journal of Chemistry, 26(8), 2471 (2014).

5. Baljeet Singh Patial, International Journal of Computational Engineering Research, 5(4), 2250 (2015).

6. Vardhana Syamala, Damaramadugu Raja Sekhar, Kasibhatta Siva Kumar and Ponneri Venkateswarlu Volumetric, Chinese Journal of Chemistry, 25(1),32 (2007).

7. Maimoona Yasmin, Journal Solution Chemistry, 40(8), 1458 (2011).

[RJC-1605/2017] 